\title{
The Fit between Technology Management and Technological Capability and Its Impact on New Product Development Performance
}

\author{
Qian $\mathrm{Ma}^{1}$, Weiwei $\mathrm{Wu}^{1}$ and Yexin $\mathrm{Liu}^{2, *}$ \\ 1 School of Management, Harbin Institute of Technology, Harbin 150001, China; 18BG10008@hit.edu.cn (Q.M.); \\ wuweiwei@hit.edu.cn (W.W.) \\ 2 School of Economics and Management, Harbin Institute of Technology at Weihai, Weihai 264209, China \\ * Correspondence: 15B910042@hit.edu.cn
}

check for updates

Citation: Ma, Q.; Wu, W.; Liu, Y. The Fit between Technology Management and Technological Capability and Its Impact on New Product Development Performance. Sustainability 2021, 13, 10956. https://doi.org/10.3390/ su131910956

Academic Editor: Luigi Aldieri

Received: 12 September 2021

Accepted: 29 September 2021

Published: 2 October 2021

Publisher's Note: MDPI stays neutral with regard to jurisdictional claims in published maps and institutional affiliations.

Copyright: (c) 2021 by the authors. Licensee MDPI, Basel, Switzerland. This article is an open access article distributed under the terms and conditions of the Creative Commons Attribution (CC BY) license (https:/ / creativecommons.org/licenses/by/ $4.0 /)$.

\begin{abstract}
In recent years, the impact of technology management and technological capability on new product development performance has aroused widespread concern. As a result, research models based on the notion of fit between technology management and technological capability seems to show promise. This paper aims to whether there exists a fit between technology management and technological capability and the effect of this fit on new product development performance. Research results show that the fit between technology management and technological capability has a positive effect on new product development performance. Moreover, the fit between technology management and technological capability in firms with high new product development performance is dominated by technological capability, while that in firms with low new product development performance is dominated by technology management.
\end{abstract}

Keywords: technology management; technological capability; fit; new product development performance

\section{Introduction}

Currently, it is widely accepted that new product development is critical to the competitive advantage of a firm [1,2]. With such a close link, more and more firms are investing a lot of resources into new product development in order to obtain sustainable competitive advantage. However, new product development is a risky activity, which results in low success rates [3]. Many new product development projects are terminated in the development cycle [4]. Therefore, it is important for firms to understand how to develop new product development successfully.

A large amount of literature has explored how to drive new product development, emphasizing technology management and technological capability [5]. For instance, Levin and Barnard (2008) indicate that technology management can help firms integrate various corporate activities, which contributes to resolving the problem of poor communication in the process of new product development [6]. Cetindamar et al. (2016) argue that all technology management activities are related to innovation, and it can promote knowledge flows between different functions, such as technological function and commercial function [7]. Therefore, technology management can reduce new product development time and thus improve new product development performance [8]. Technological capability is an important kind of knowledge, which is critical for firms to generate new knowledge for innovation [9]. Technological capability is also related to the using of technological knowledge, and it argues that firms with higher level of technological capability tend to have higher level of absorptive capacity [10] Therefore, technological capability could increase existing knowledge of a firm, and thus produce a higher likelihood of succeeding in new product development [11]. 
Although the current research has widely accepted the important roles of technology management and technological capability in new product development, most of them only explore the effect of technology management or technological capability on new product development separately. However, from the resource-based view, the fit between technology management and technological capability in new product development should be investigated [12]. It is argued that technological capability is one of the most important resources for new product development, while technology management is a process that develops and implements technological capability continuously [13]. Therefore, technology management and technological capability is supposed to have an inner relationship in the process of new product development. However, few studies explore the fit between technology management and technological capability and its effects on new product development performance. This leaves the fit between technology management and technological capability poorly understood.

Bridging the current research gap, this paper explores whether the fit between technology management and technological capability is related to new product development performance. Following the introduction, Section 2 provides the theoretical foundation and develops the hypotheses of this paper. Then, Section 3 describes the methodology used in this paper. The proposed hypotheses are verified in Section 4 and the research results are discussed in Section 5. The Section 6 provides conclusions, theoretical contributions and managerial implications, and limitations and further research.

\section{Theoretical Foundation and Hypotheses Development}

\subsection{Fit}

Fit is an important concept in management research [14]. For instance, the concept of fit serves the building block in contingency theory, because it can explain why different firms achieve different performance [15]. Theoretically, fit can be defined as the matching between two or more related variables [16]. Based on this understanding, the fit between technology management and technological capability can be defined as the way technology management and technological capability adapting to each other to achieve higher level of matching. According to the relationship between fit and performance, it can be proposed that the higher level of the fit between technology management and technological capability, the higher level of new product development performance.

According to Venkatraman (1989) [17], six kinds of fit can be used in research, including fit as moderation, fit as mediation, fit as matching, fit as covariation, fit as profile deviation, and fit as gestalts. These six kinds of fit can be classified from three dimensions, namely the number of variables incorporated, the functional form of calculation, and the presence-or absence-of a criterion variable. In this paper, the concept of fit is consistent with definition of matching, which is the congruency interaction between technology management and technological capability.

\subsection{Technology Management}

Technology management studies can be traced back to the early 1970s. With years of development, technology management has evolved from initial R\&D management to strategic management of technology [18]. According to the National Research Council [19], technology management "links engineering, science, and management disciplines to plan, develop, and implement technological capabilities to shape and accomplish the strategic and operational objectives of an organization". It is usually argued that technology management includes several generic processes, which includes identification, selection, acquisition, exploitation, protection [20], and learning [21]. This implies that the technology management has close correlations with multiple kinds of knowledge, such as strategic management, organizational management and innovation management [22].

In this paper, we adopt the definition given by National Research Council and regard technology management as the capability to plan, develop, exploit and implement technological capability that aims to improve a firm's competitiveness. 


\subsection{Technological Capability}

Technological capability, mainly manifested by technological knowledge [23], is one of the most important resources that a firm needs to manage [24]. It is widely accepted that the cornerstone of firm innovation lies in its technological knowledge [25], and thus technological capability can be seen as a driving force of innovation. Moreover, a firm with strong technological capability always tends to own stronger ability to perform all activities entailed in new product development [26]. A firm with strong technological capability can also gain resources more easily for its new product development by getting a clearer understanding of technological changes and identifying new technology opportunities from the technological changes [27]. Therefore, technological capability is vital for firms to develop a series of continuous innovations.

Following previous research, we define technological capability as the technological knowledge that firms own. It enables firms to create innovation that customers may value.

\subsection{The Effect of the Fit between Technology Management and Technological Capability on New Product Development Performance}

From the resource-based view, firms obtain sustained competitive advantages from the resources and capabilities they own [28]. Technological capability is the technological resources within the organization, while technology management can ensure the technological resources including soft resources, such as knowledge, and hard resources, such as equipment, are aligned with its needs [29]. Therefore, technological capability can be regarded as the object that technology management works on, and technology management and technological capability is associated with fit [30]. In new product development, the relationship between technology management and technological capability can fulfill the management need of a specific set of technological resources, which can further improve new product development performance.

Furthermore, technological capability relates to a set of differentiated skills that form the basis for the firms' sustainable advantages [31]. In that process, technological capability can bring new opportunities for new product development continuously [32]. However, these new opportunities need to be captured and converted by technology management [33]. Technology management enables a firm to absorb, employ, adjust and shift existing technologies [34], and it also helps a firm to create new technologies [35]. Therefore, firms can develop new products through the fit between technology management and technological capability to the market and achieve the first-mover advantage.

Overall, technology management and technological capability are complementary to meet the challenge of the changing world. New product development requires technological capability to support production and engineering [36], and it also needs effective technology management concerning both strategic and operational issues to provide a framework to develop and implement technological capability [37]. If the firm only relies on technological capability and ignores technology management in new product development, it tends to spend too many resources in innovation activities without fully meeting the market demands and the requirements of business development [38]. Therefore, it can be seen that technology management and technological capability are interrelated with each other, and the more interrelated they are, the higher new product development performance. Based on the above theoretical analysis, this paper thus posits the following hypotheses:

Hypothesis (H1). The fit between technology management and technological capability has a positive impact on new product development performance.

Hypothesis (H2). The deviation between technology management and technological capability has a negative impact on new product development performance. 


\section{Methodology}

\subsection{Sample and Data Collection}

This paper tests the hypotheses by questionnaire survey. The questionnaire survey was conducted in Chinese manufacturing firms as the demonstration examples. The questionnaire used for data collection was pre-tested with five chief executive officers. After the pre-test, some items in the questionnaire were rearranged and reworded. The senior managers may have a more comprehensive understanding about a firm's technology management, technological capability and new product development performance. Therefore, the respondents of the questionnaire were senior managers in the firm. Initially, we sent out 180 questionnaires. In order to improve the response rate, we contacted the senior managers participated in the questionnaire survey to get their consent. Three weeks after they received the questionnaire, we sent them the same questionnaire again as a reminder. Finally, 153 questionnaires were collected.

\subsection{Measurement}

3.2.1. Measurement of Technology Management and Technological Capability

Technology management is measured by the instrument developed by $\mathrm{Wu}$ et al. (2012) [5]. We use a 13-item instrument from Yu et al. (2013) [39] to measure technological capability. The items are shown in Appendix A. Each of the scale is a 5-point scale, in which 1 equals to disagree and 5 equals to agree.

\subsubsection{Measurement of Fit}

The fit in this paper is tested by subgroup analysis. According to Sharma et al. (1981) [40] and Argote (1982) [41], the fit can be proved if the correlation coefficients in different subgroups are different. Accordingly, we firstly split our sample firms into two performance subgroups: firms with high new product development performance and firms with low new product development performance. Then, the correlation coefficients between technology management and technological capability in these two subgroups were calculated. In this way, it can be shown whether the fit between technology management and technological capability is more related to higher new product development performance [17].

The deviation between technology management and technological capability is measured by the deviation score, which is consistent with the matching definition provided by Venkatraman (1989) [17].

\subsubsection{Measurement of New Product Development Performance}

The new product development performance is measured by the scale of Hsu (2009) [42], with a 5-point scale where 1 equals to disagree and 5 equals to agree. The items are shown in Appendix A.

We also include two control variables in the regression analysis, namely firm size and type of industry. In innovation research, it is important to control firm size, measured by the number of firm employees in this paper [43], because larger firms always tend to own more resources to invest into new product development [44]. Type of industry is an important control variable because different firms conduct different technology management practices [45]. The respondents in this paper are divided by high-technology industries and non-high-technology industries, and are controlled by using dummy variables.

\subsection{Validity and Reliability}

Table 1 shows the descriptive statistics of technology management, technological capability and new product development performance, including means, standard deviation, and correlation coefficients. Table 1 also presents the Cronbach's $\alpha$ value and the square root of AVE. 
Table 1. Descriptive Statistics.

\begin{tabular}{|c|c|c|c|c|c|c|}
\hline Variables & Mean & SD & 1 & 2 & 3 & Cronbach's $\alpha$ \\
\hline 1. Technology management & 3.613 & 0.856 & 0.991 & & & 0.967 \\
\hline 2. Technological capability & 3.509 & 0.903 & $0.667^{* * *}$ & 0.960 & & 0.803 \\
\hline 3. New product development performance & 3.589 & 1.062 & $0.896^{* * *}$ & $0.860^{* * *}$ & 1 & 0.780 \\
\hline
\end{tabular}

As Table 1 shows, the Cronbach's $\alpha$ of technology management, technological capability and new product development performance all exceed 0.7 , which indicates that the reliability can be accepted.

This paper collects the items from high quality academic journals. In order to assure the content validity, the initial questionnaire was sent to several scholars who are familiar with the related literature. Following their suggestions, several minor modifications was made to the questionnaire. Then, the revised questionnaire was sent to several executives for advice. Based on their feedback, the questionnaire was rearranged and reworded for some items. These interviews construct the basis of the content validity of the questionnaire.

The discriminant validity between the variables is proved by the square root of AVE. As shown in Table 1, the square root of AVE is greater than the corresponding correlation coefficients.

In order to avoid the potential common method variance, we followed the advice of Podsakoff et al. (2003) [46] to take several procedural remedies. In the questionnaire design, we only included the well-established items and tried to reduce the contextual cues by separating dependent variable and independent variables [47]. We also make it clear for the respondents that their answers are neither right nor wrong and allow anonymous participation [48].

\section{Results}

SPSS 24.0 was used to analyze the data. We divided the samples into two groups according to the mean value of new product development performance. The firms whose new product development performance is lower than the mean value are in the low new product development performance group; otherwise, they are in the high new product development performance group. According to Bergeron (2001) [15], correlation coefficient between the variables can be used as a measurement of whether the variables fit or not. Therefore, we firstly calculate the correlation coefficient of technology management and technological capability. The results are shown in Table 2.

Table 2. Correlation coefficients of technology management and technological capability.

\begin{tabular}{ccc}
\hline Correlation Coefficient & $\begin{array}{c}\text { Technology Management } \\
\text { (High New } \\
\text { Product Development } \\
\text { Performance Group) }\end{array}$ & $\begin{array}{c}\text { Technology Management } \\
\text { (Low New } \\
\text { Product Development } \\
\text { Performance Group) }\end{array}$ \\
\hline Technological capability & $0.668^{* * *}$ & $0.446^{* *}$ \\
\hline Note: ${ }^{* *} p<0.01,{ }^{* *} p<0.05$ (2-tailed). &
\end{tabular}

Table 2 shows that, in the high new product development performance, the fit degree of technology management and technological capability is very high $(0.668, p<0.01)$. Meanwhile in the low new product development performance, the fit degree of technology management and technological capability is relatively low $(0.446, p<0.05)$. This implies a strong correlation between the fit and new product development performance. That is, the stronger the fit between technology management and technological capability is, the higher new product development performance is. This result supports Hypothesis 1. 
In order to further explore the effect of the deviation between technology management and technological capability on new product development performance, we applied the matching method to construct the following regression model.

$$
\mathrm{Y}=\alpha+\beta \mathrm{X} 1+\gamma \mathrm{X} 2+\delta|\mathrm{ZX} 1-\mathrm{ZX} 2|+\varepsilon
$$

where $\mathrm{Y}$ represents new product development performance; $\mathrm{X} 1$ represents technology management; X2 represents technological capability; |ZX1 - ZX2 | indicates the deviation degree of between technology management and technological capability. The regression results are shown in Table 3.

Table 3. Results of the deviation between technology management and technological capability.

\begin{tabular}{lll}
\hline \multicolumn{1}{c}{ Variables } & \multicolumn{1}{c}{ Coefficient } \\
\cline { 2 - 3 } & $\begin{array}{l}\text { High New Product } \\
\text { Development } \\
\text { Performance Group }\end{array}$ & $\begin{array}{l}\text { Low New Product } \\
\text { Development } \\
\text { Performance Group }\end{array}$ \\
\hline Technology management & $0.305^{* *}$ & $0.594^{* * *}$ \\
Technological capability & $0.481^{* * *}$ & $0.303^{* *}$ \\
Deviation & $-0.250^{* *}$ & $-0.278^{* *}$ \\
Firm size & 0.052 & 0.068 \\
Type of industry & 0.150 & 0.038 \\
F & $21.203^{* * *}$ & $23.529 * * *$ \\
R Square & 0.702 & 0.797 \\
Adjusted R Square & 0.669 & 0.763 \\
\hline Note* $* * x<0.05^{* * *} p<0.01$ & &
\end{tabular}

Table 3 shows that, in high new product development performance group, technology management $(\beta=0.305, p<0.05)$ and technological capability $(\beta=0.481, p<0.01)$ both have positive impacts on new product development performance, while the deviation between technology management and technological capability has a negative impact on new product development performance $(\beta=-0.250, p<0.05)$. In low new product development performance group, technology management $(\beta=0.594, p<0.01)$ and technological capability $(\beta=0.303, p<0.05)$ both also have positive impacts on new product development performance, and the deviation between technology management and technological capability also has a negative impact on new product development performance $(\beta=-0.278$, $p<0.05)$. These lead to the conclusion that the deviation between technology management and technological capability is negatively related to new product development performance, which supports Hypothesis 2.

\section{Discussion}

The results of this paper firstly show that the fit between technology management and technological capability has a positive impact on new product development performance. Technological capability is of significance to new product development, while technology management could manage and leverage technological capability. Therefore, the fit between technology management and technological capability will be a predictor of new product development performance, which suggests adjusting both technology management and technological capability to a more developed level, the new product development performance will be greater. We can use Harbin Electric Corporation (HEC) as an example to further illustrate this point. HEC, one of the most successful innovative firms in China, has achieved successful hydrogenerator development by emphasizing the fit between its technology management and technological capability. HEC's acquisition of technological capability is always accompanied by the acquisition of related management philosophy. To be specific, HEC's management systems are all made based on the its technological capability. Its organizational structure and corporate culture are centered on technological development. Its regulations, such as training regulations and incentive 
regulations all aim at providing long term guarantees for its technological capability. In the journey of new product development, HEC integrate technology management and technological capability to achieve their proper fit, and further achieve successful independent innovation in developing huge water-wheel generator sets.

While the deviation will be associated with low effectiveness [49]. New product development, as a complex activity entailing numerous uncertainties, requires interdependencies between different functions [50]. The deviation between technology management and technological capability means the lack of integration between technological issues and managerial functions [51], which thus will further affect new product development performance. The goal of technology management is to synergize all the functions (i.e., R\&D, planning, engineering, and production) and make them work together in the most efficient way to enhance and activate technological capability [52]. In the new product development process, critical technology management activities include strategic planning for new products, careful selection of new product projects, organizational learning about new technological knowledge, creating conducive learning culture, and coordinating of new product development teams [53]. These activities exert great influences on the accumulation and cultivation of technological capability [54]. Therefore, the deviation between technology management and technological capability can be seen as a waste of resources. That is to say that even if an effort is made to implement technology management (technological capability), it is not providing all the potential benefits because technological capability (technology management) does not follow in its own implementation. The failure to achieve a fit would lead to inferior results, meaning that technology management and technological capability cannot properly play their roles in new product development.

In addition, we also find that in the high new product development performance group, the value of the coefficient of technology management $(0.305)$ is much smaller than technological capability (0.481), implying that technological capability is the most important force impelling the firms to gain high new product development performance. Therefore, it might be inferred that the fit between technology management and technological capability is dominated by technological capability. This may be because that firms with high new product development performance have high technology management level, which provides favorable conditions for technological capability to fully play its role. In this regard, we argue that once technology management exceeds a certain threshold, technological capability is the more important factor that influences new product development performance, since technology management cannot be transformed directly into new products. Thus, firms in the high new product development performance group should pay more attention to the development of technological capability in order to achieve their technological advantages to promote new product development performance.

Meanwhile, in the low new product development performance group, technology management plays the most important role in affecting new product development performance since its coefficient value is much greater (0.594) than the coefficient value of TC (0.303). This indicates that the fit between technology management and technological capability of firms with low new product development performance might be dominated by technology management. This can be explained by the essence of technology management, which is the implementation and development of technological capability. In other words, the potential of technological capability must be activated by technology management to be transformed into new product development. In the firms with low new product development performance, technology management is also low. The low level of technology management may limit the effect of technological capability on new product development performance, and only when technology management is elevated to high levels does technological capability become more valuable, because high level technology management can help firms to better perceive the changing trends of technological knowledge. Thus, the internal and external technology bases can be fully accumulated and exploited [55]. Firms with low new product development performance should firstly improve technology management. 
Our findings imply that technology management and technological capability should be treated differently in consideration of contingency. We specify this conclusion from the perspective of firm life cycle, and we argue that with the firm's evolution, the firm should adjust its focus between technology management and technological capability. In the early life cycle stages, although the firm invests all available resources in developing the new products, the growth of new product development performance is likely to be slow [56]. Under such conditions, firms should pay more attention to enhancing technology management since it is the foundation for technological capability to exert its effects. Thereafter, firms' new product development performance will grow rapidly. Meanwhile, in order to maintain growth, firms have to generate new products by promoting the technological capability to maintain its technological competitiveness, since competitors will adopt and improve on the pioneering firm's new products. Therefore, the firms' focus should be shifted to technological capability. However, this shift must be based on a high level of technology management, which is developed in the early stages. This can explain why many Chinese firms spend a great deak of resources in improving their technological capability but remain relatively weak in new product development and have poor new product development performance.

\section{Conclusions}

This paper explores the effect of the fit between technology management and technological capability on new product development performance. The results show that the fit between technology management and technological capability has a positive effect on new product development performance, while the deviation between technology management and technological capability has a negative effect on new product development performance. Furthermore, the roles of technology management and technological capability are different in different new product development performance groups. To be specific, technological capability dominates the fit in the firms with high new product development performance, while technology management dominates the fit in the firms with low new product development performance.

\subsection{Theoretical Contributions}

This paper investigates the effect of the fit between technology management and technological capability on new product development performance, and the findings contribute to the literature in several ways.

Firstly, this paper expands our understanding of the relationship between technology management and technological capability. Previous studies have pointed out that there exists a coupling relationship between technology management and technological capability, and the coupling relationship is in the form of double helix [5]. This paper reveals that there also exists a fit between technology management and technological capability, implying that the fit between technology management and technological capability should be the main reason for the formation of their double helix coupling model. Therefore, this paper enriches and deepens prior research by proposing the importance of the fit between technology management and technological capability.

Secondly, this paper contributes to the literature on new product development by demonstrating the antecedent effect of the fit between technology management and technological capability. Prior new product development studies that relate to the fit mainly focus on the effects of the interactions of different functions such as marketing, R\&D, sales, manufacturing $[57,58]$. However, the fit between technology management and technological capability is rarely mentioned. This paper empirically reveals a direct and positive relationship between the fit between technology management and technological capability and new product development performance. This paper thus identified a new antecedent of new product development performance, and further encourages theoretical developments on the fit of other elements. 
Thirdly, this paper further deepens the understanding of how the fit between technology management and technological capability exerts its impact on new product development performance by revealing the effects of technology management and technological capability in high new product development performance group and low new product development performance group separately. This paper reveals that technological capability plays a more important role when a firm's new product development performance is high, while technology management plays a more important role when a firm's new product development performance is low. As such, this paper extends the understanding of boundary conditions of the fit between technology management and technological capability, which highlight a new perspective for further product innovation studies.

\subsection{Managerial Implications}

The research results also offer some insights for firms about how to employ technology management and technological capability to improve new product development performance. The findings highlight the importance of the fit between technology management and technological capability, such that firms with better fit are prone to achieve better new product development performance. Thus, firms should enhance their technology management, technological capability and the fit between them. From the technology management perspective, the possible practices that can be employed include paying particular attention on resource acquisition, creating favorable organization culture, establishing total quality management system. From the perspective of technological capability, the possible practices that can be employed include recruiting more R\&D employees, constructing information networks, updating firm's equipment and optimizing organizational structure.

The results also reveal the contingency of the fit between technology management and technological capability. Our findings show that the fit is dominated by technological capability when new product development performance is high, and by technology management when new product development performance is low. These suggest that in order to promote new product development performance, the firm should firstly evaluate its new product development performance. If the new product development performance is relatively low compared with the average performance of other firms, then the firm should firstly promote its technology management to a certain level and then promote technological capability to achieve matching. In this way, our results provide a new method for the firm to improve new product development.

\subsection{Limitations and Further Research}

This paper has the following shortcomings. Firstly, the samples are mostly manufacturing firms, and thus the conclusions of this paper may be more applicable for manufacturing firms. Other types of firms can be included to testify the generalization of our results. Secondly, the research model can be further advanced by incorporating other relevant mediators and moderators that may mediate or moderate the relationship between the fit and new product development performance. Thirdly, this paper does not take factors that are outside the firm into consideration. The environmental characteristics that may have impacts on technology management, technological capability and new product development performance could also be incorporated in order to obtain more complete research results.

Author Contributions: Conceptualization, Y.L.; methodology, Q.M.; original draft preparation, Y.L. and Q.M.; review and editing, W.W. All authors have read and agreed to the published version of the manuscript.

Funding: This work was supported by National Natural Science Foundation of China (72072047), the humanities and social sciences project of MOE (20YJC630090), and Heilongjiang Philosophy and Social Science Research Project (19GLB087).

Institutional Review Board Statement: Not applicable.

Informed Consent Statement: Not applicable. 
Conflicts of Interest: The authors declare no conflict of interest.

\section{Appendix A}

Table A1. The measurement of technology management, technological capability and new product development performance.

\begin{tabular}{ll}
\hline Constructs & Measurement Items \\
\hline & $\begin{array}{l}\text { Fund procurement; fund utilization efficiency; equipment management; technician } \\
\text { development strategy; technology manager; technician management; technician } \\
\text { team building; technician communication mechanism; technology information }\end{array}$ \\
& $\begin{array}{l}\text { acquisition; information archiving; results assessment; patent application; } \\
\text { technological innovation-focused culture; organization-technology fit; technological } \\
\text { Technology management } \\
\text { collaboration; planning technological activities; total quality management system; } \\
\text { technology standard system; technology standards implementation; technology } \\
\text { risk management }\end{array}$ \\
& $\begin{array}{l}\text { Number of scientific and technical personnel; number of senior technicians; age } \\
\text { structure; level of knowledge; level of information network; number of technical } \\
\text { files; degree of technical file meets R\&D demand; soundness of the current } \\
\text { equipment; number of equipment at international advanced level; quality and } \\
\text { experience of management; number of R\&D departments; R\&D funding availability; } \\
\text { adequacy of technology for product }\end{array}$ \\
\hline New product development performance & \begin{tabular}{l} 
Product leadership; product development cycle; cost of product; product success rate \\
\hline
\end{tabular} \\
\hline
\end{tabular}

\section{References}

1. Ramadani, V.; Hisrich, R.D.; Abazi-Alili, H.; Dana, L.-P.; Panthi, L.; Abazi-Bexheti, L. Product innovation and firm performance in transition economies: A multi-stage estimation approach. Technol. Forecast. Soc. Chang. 2019, 140, 271-280. [CrossRef]

2. Heij, C.V.; Volberda, H.W.; van den Bosch, F.A.J.; Hollen, R.M.A. How to leverage the impact of R\&D on product innovation? The moderating effect of management innovation. RD Manag. 2020, 50, 277-294. [CrossRef]

3. Cormican, K.; O'Sullivan, D. Auditing best practice for effective product innovation management. Technovation 2004, 24, 819-829. [CrossRef]

4. Eling, K.; Griffin, A.; Langerak, F. Consistency matters in formally selecting incremental and radical new product ideas for advancement. J. Prod. Innov. Manag. 2016, 33, 20-33. [CrossRef]

5. Wu, W.W.; Yu, B.; Wu, C. How China's equipment manufacturing firms achieve successful independent innovation: The double helix mode of technological capability and technology management. Chin. Manag. Stud. 2012, 6, 160-183. [CrossRef]

6. Levin, D.Z.; Barnard, H. Technology management routines that matter to technology managers. Int. J. Technol. Manag. 2008, 41, 22-37. [CrossRef]

7. Cetindamar, D.; Phaal, R.; Probert, D.R. Technology management as a profession and the challenges ahead. J. Eng. Technol. Manag. 2016, 41, 1-13. [CrossRef]

8. Li-Hua, R.; Khalil, T.M. Technology management in China: A global perspective and challenging issues. J. Technol. Manag. China 2006, 1, 9-26. [CrossRef]

9. Jin, J.; Von Zedtwitz, M. Technological capability development in China's mobile phone industry. Technovation 2008, 28, 327-334. [CrossRef]

10. Kang, T.; Baek, C.; Lee, J.D. The persistency and volatility of the firm R\&D investment: Revisited from the perspective of technological capability. Res. Policy 2017, 46, 1570-1579. [CrossRef]

11. Aydin, H. Market orientation and product innovation: The mediating role of technological capability. Eur. J. Innov. Manag. 2020, 24, 1233-1267. [CrossRef]

12. Barney, J.B.; Ketchen, D.J., Jr.; Wright, M. The future of resource-based theory: Revitalization or decline? J. Manag. 2011, 37, 1299-1315. [CrossRef]

13. Cetindamar, D.; Phaal, R.; Probert, D. Understanding technology management as a dynamic capability: A framework for technology management activities. Technovation 2009, 29, 237-246. [CrossRef]

14. Burkert, M.; Davila, A.; Mehta, K.; Oyon, D. Relating alternative forms of contingency fit to the appropriate methods to test them. Manag. Account. Res. 2014, 25, 6-29. [CrossRef]

15. Ortega, C.H.; Garrido-Vega, P.; Machuca, J.A.D. Analysis of interaction fit between manufacturing strategy and technology management and its impact on performance. Int. J. Oper. Prod. Manag. 2012, 32, 958-981. [CrossRef]

16. Bergeron, F.; Raymond, L.; Rivard, S. Fit in strategic information technology management research: An empirical comparison of perspectives. Omega 2001, 29, 125-142. [CrossRef]

17. Venkatraman, N. The concept of fit in strategy research: Toward verbal and statistical correspondence. Acad. Manag. Rev. 1989, 14, 423-444. [CrossRef] 
18. Drejer, A. The discipline of management of technology, based on considerations related to technology. Technovation 1997, 17, 253-265. [CrossRef]

19. National Research Council. Management of Technology: The Hidden Competitive Advantage; The National Academy Press: Washington, DC, USA, 1987.

20. Phaal, R.; Farrukh, C.J.P.; Probert, D.R. Technology management process assessment: A case study. Int. J. Oper. Prod. Manag. 2001, 21, 1116-1132. [CrossRef]

21. Çetindamar, D.; Phaal, R.; Probert, D. Technology Management: Activities and Tools; Palgrave Macmillan: New York, NY, USA, 2010.

22. Sahlman, K.; Haapasalo, H. Elements of strategic management of technology: A conceptual framework of enterprise practice. Int. J. Manag. Enterp. Dev. 2009, 7, 319-337. [CrossRef]

23. Wu, J.; Ma, Z.; Liu, Z. The moderated mediating effect of international diversification, technological capability, and market orientation on emerging market firms' new product performance. J. Bus. Res. 2019, 99, 524-533. [CrossRef]

24. Kiamehr, M. Paths of technological capability building in complex capital goods: The case of hydro electricity generation systems in Iran. Technol. Forecast. Soc. Chang. 2017, 122, 215-230. [CrossRef]

25. Hsieh, M.H.; Tsai, K.H. Technological capability, social capital and the launch strategy for innovative products. Ind. Mark. Manag. 2007, 36, 493-502. [CrossRef]

26. Sears, J.; Hoetker, G. Technological overlap, technological capabilities, and resource recombination in technological acquisitions. Strateg. Manag. J. 2014, 35, 48-67. [CrossRef]

27. Zhou, K.Z.; Wu, F. Technological capability, strategic flexibility, and product innovation. Strateg. Manag. J. 2010, 31, 547-561. [CrossRef]

28. Barney, J.; Wright, M.; Ketchen, D.J. The resource-based view of the firm: Ten years after 1991. J. Manag. 2001, $27,625-641$. [CrossRef]

29. Farrukh, C.; Phaal, R.; Probert, D. Technology roadmapping: Linking technology resources into business planning. Int. J. Technol. Manag. 2003, 26, 2-19. [CrossRef]

30. Bhatt, G.D. Knowledge management in organizations: Examining the interaction between technologies, techniques, and people. J. Knowl. Manag. 2001, 5, 68-75. [CrossRef]

31. Srivastava, M.K.; Gnyawali, D.R.; Hatfield, D.E. Behavioral implications of absorptive capacity: The role of technological effort and technological capability in leveraging alliance network technological resources. Technol. Forecast. Soc. Chang. 2015, 92, 346-358. [CrossRef]

32. Tang, G.X.; Park, K.; Agarwal, A.; Liu, F. Impact of innovation culture, organization size and technological capability on the performance of SMEs: The Case of China. Sustainability 2020, 12, 1355. [CrossRef]

33. Kerr, C.; Farrukh, C.; Phaal, R.; Probert, D. Key principles for developing industrially relevant strategic technology management toolkits. Technol. Forecast. Soc. Chang. 2013, 80, 1050-1070. [CrossRef]

34. Kim, W. The current transition in management of technology education: The case of Korea. Technol. Forecast. Soc. Chang. 2015, 100, 5-20. [CrossRef]

35. Oerlemans, L.A.G.; Knoben, J.; Pretorius, M.W. Alliance portfolio diversity, radical and incremental innovation: The moderating role of technology management. Technovation 2013, 33, 234-246. [CrossRef]

36. Eng, T.Y.; Okten, D. Exploring a dynamic framework of innovative capability: A theoretical integration of technological and marketing capabilities. Technol. Anal. Strateg. Manag. 2011, 23, 1001-1013. [CrossRef]

37. Phaal, R.; Kerr, C.; Oughton, D.; Probert, D. Towards a modular toolkit for strategic technology management. Int. J. Technol. Intell. Plan. 2012, 8, 161-181. [CrossRef]

38. Yam, R.; Guan, J.C.; Pun, K.F.; Tang, E.P.Y. An audit of technological innovation capabilities in Chinese firms: Some empirical findings in Beijing, China. Res. Policy 2004, 33, 1123-1140. [CrossRef]

39. Yu, B.; Hao, S.B.; Ahlstrom, D.; Si, S.; Liang, D. Entrepreneurial firms' network competence, technological capability, and new product development performance. Asia Pac. J. Manag. 2014, 31, 687-704. [CrossRef]

40. Sharma, S.; Durand, R.M.; Gur-Arie, O. Identification and analysis of moderator variables. J. Mark. Res. 1981, 18, 291-300. [CrossRef]

41. Argote, L. Input uncertainty and organizational coordination in hospital emergency units. Adm. Sci. Q. 1982, 27, 420-434. [CrossRef] [PubMed]

42. Hsu, Y.H.; Fang, W. Intellectual capital and new product development performance: The mediating role of organizational learning capability. Technol. Forecast. Soc. Chang. 2009, 76, 664-677. [CrossRef]

43. Adams, P.; Freitas IM, B.; Fontana, R. Strategic orientation, innovation performance and the moderating influence of marketing management. J. Bus. Res. 2019, 97, 129-140. [CrossRef]

44. Jin, Z.; Navare, J.; Lynch, R. The relationship between innovation culture and innovation outcomes: Exploring the effects of sustainability orientation and firm size. RD Manag. 2019, 49, 607-623. [CrossRef]

45. Wu, W.W.; Liang, D.P.; Yu, B. Strategic planning for management of technology of China's high technology enterprises. In Proceedings of the PICMET '08 - 2008 Portland International Conference on Management of Engineering \& Technology, Cape Town, South Africa, 27-31 July 2008; p. 10146390.

46. Podsakoff, P.M.; MacKenzie, S.B.; Lee, J.Y.; Podsakoff, N.P. Common method biases in behavioral research: A critical review of the literature and recommended remedies. J. Appl. Psychol. 2003, 88, 879-903. [CrossRef] [PubMed] 
47. Spector, P.E. Method variance in organizational research: Truth or urban legend? Organ. Res. Methods 2006, 9, 221-232. [CrossRef]

48. Malhotra, N.K.; Kim, S.S.; Patil, A. Common method variance in IS research: A comparison of alternative approaches and a reanalysis of past research. Manag. Sci. 2006, 52, 1865-1883. [CrossRef]

49. Fulmer, I.S.; Barry, B.; Long, D.A. Lying and smiling: Informational and emotional deception in negotiation. J. Bus. Ethics 2009, 88, 691-709. [CrossRef]

50. Hirunyawipada, T.; Beyerlein, M.; Blankson, C. Cross-functional integration as a knowledge transformation mechanism: Implications for new product development. Ind. Mark. Manag. 2010, 39, 650-660. [CrossRef]

51. Millson, M.R.; Wilemon, D. The impact of organizational integration and product development proficiency on market success. Ind. Mark. Manag. 2002, 31, 1-23. [CrossRef]

52. Argote, L.; Hora, M. Organizational learning and management of technology. Prod. Oper. Manag. 2017, 26, 579-590. [CrossRef]

53. Scott, G.M. Critical Technology management issues of new product development in high-tech companies. J. Prod. Innov. Manag. 2000, 17, 57-77. [CrossRef]

54. Madanmohan, T.R.; Kumar, U.; Kumar, V. Import-led technological capability: A comparative analysis of Indian and Indonesian manufacturing firms. Technovation 2004, 24, 979-993. [CrossRef]

55. Farrukh, C.; Fraser, P.; Hadjidakis, D.; Phaal, R.; Probert, D.; Tanish, D. Developing an integrated technology management process. Res. Technol. Manag. 2004, 47, 39-46. [CrossRef]

56. Yoo, J.; Lee, S.; Park, S. The Effect of Firm Life Cycle on the Relationship between R\&D Expenditures and Future Performance, Earnings Uncertainty, and Sustainable Growth. Sustainability 2019, 11, 2371. [CrossRef]

57. Genç, E.; DiBenedetto, C.A. Cross-functional integration in the sustainable new product development process: The role of the environmental specialist. Ind. Mark. Manag. 2015, 50, 150-161. [CrossRef]

58. Weber, B.; Heidenreich, S. When and with whom to cooperate? Investigating effects of cooperation stage and type on innovation capabilities and success. Long Range Plan. 2018, 51, 334-350. [CrossRef] 